\title{
CONCEPÇÕES DE TERRITÓRIO E TERRITORIALIDADE NO ANTIGO NORTE GOIANO
}

\author{
T. S. SALES ${ }^{1}$, R. D. GUALBERTO ${ }^{2}$ \\ Universidade Federal do Tocantins ${ }^{1,2}$ \\ tamnass@gmail.com ${ }^{1}$
}

Artigo submetido em 01/08/2017 e aceito em 20/08/2019

DOI: $10.15628 /$ holos.2019.6177

\begin{abstract}
RESUMO
O trabalho consistiu em uma revisão bibliográfica, realizada a partir de diferentes fontes de pesquisa tais como: análise nos Relatórios Administrativos da Província de Goiás no século XIX e de diálogos entre alguns autores, como Raffestin (1993), Saquet (2007a), Haesbaert (2007) e outros. O presente texto teve por objetivo analisar as concepções dos termos território e territorialidade; buscando estabelecer uma contextualização histórica/geográfica sobre estas concepções interligadas na noção dos conceitos de desterritorialização dos indígenas no antigo norte goiano
\end{abstract}

no século XIX. Os estudos encontrados mostram que as tomadas dos territórios dos indígenas pelo Governo e para o desenvolvimento da província de Goiás no século XIX proporcionaram à história uma diversidade de fatos voltados para o conflito e para a resistência, seja pelo indígena para a sua permanência a território ocupado, levando em conta sua sobrevivência, cultura, economia entre outros, seja pelo não indígena que a dominou posteriormente construindo ali uma nova concepção de território ocupado.

PALAVRAS-CHAVE: Resistência, Desterritorialização, Indígenas.

\section{CONCEPTIONS OF TERRITORY AND TERRITORIALITY IN THE OLD NORTH GOIANO}

\section{ABSTRACT}

The work consisted of a bibliographical review, carried out from different sources of research such as: analysis in the Administrative Reports of the Goiás Province in the period of the nineteenth century and dialogues among some authors, such as Raffestin (1993); Saquet (2007a); Haesbaert (2007) and others. The present text had as objective to analyze the conceptions of the terms territory and territoriality; Seeking to establish a historical / geographical contextualization on these conceptions interconnected in the notion of the concepts of deterritorialization of the indigenous in the old
\end{abstract}

northern Goian in the period of century XIX. The studies found show that the taking of the territories of the indigenous by the state by and for the development of the province of Goiás in the nineteenth century provided to the history a diversity of facts geared to the conflict and to the resistance, whether by the indigenous for its permanence To occupied territory, taking into account its survival, culture, economy among others, or by the nonindigenous that dominated it later building there a new conception of occupied territory.

KEYWORDS: Territory, Territoriality, Desterritorialization, Indigenous. 


\section{INTRODUÇÃO}

Este trabalho visou em primeiro momento analisar as concepções dos termos território e territorialidade. Posteriormente buscou estabelecer uma contextualização histórico/geográfica sobre estas concepções interligadas nas concepções de tomada de territórios ocupados por povos indígenas no antigo norte goiano no século XIX.

Tendo como problematização a identificação e compreensão de como se iniciou o processo de desterritorialização no antigo norte goiano, tendo como foco as retiradas dos indígenas destes territórios e como eram vistos pelo poder provincial goiano.

Para esta análise buscamos como fonte de pesquisa os Relatórios Administrativos da Província de Goiás no século XIX. Buscamos também por meio deste trabalho estabelecer alguns diálogos entre autores que trabalham com as concepções dos termos território, territorialidade e desterritorialidade, visto que para contextualizar as concepções de (des) territorialização de um espaço ocupado ou não.

Muitas são as discussões da ciência geográfica para a definição do território e da territorialidade. Embora essas discussões em torno dessas concepções não se constitua uma novidade nos campos geográficos. O território, por estar relacionado aos processos de construção e transformação do espaço geográfico, se tornou um dos principais conceitos utilizados na Geografia. Para Raffestin (1993) o seu conceito está relacionado por meio de uma relação de poder.

Centrado no que Raffestin (1993) compreende que o território se apoia no espaço, mas não é o espaço. É uma produção, a partir do espaço. O território é o espaço apropriado por uma relação de poder, ou seja, quando um indivíduo ou uma organização exerce um controle ou um poder sobre um determinado campo.

Nessa perspectiva, quando um determinado espaço for ocupado, ele territorializa uma ação e consequentemente este espaço agora se torna um território. Assim, a territorialidade é constituída nas formas das relações diárias e cotidianas por momentos que permanecemos entre nós e da percepção que temos diante de um poder exercido por alguém.

Dessa forma, o trabalho está organizado em duas seções, primeiro traz algumas discussões acerca dos conceitos de território e territorialidade, logo após traz alguns argumentos sobre a desterritorialidade tendo como foco os povos indígenas no antigo norte goiano e seus processos. 


\section{CONCEPÇÕES DE TERRITÓRIO E TERRITORIALIDADE}

As discussões que envolvem estes dois termos são amplas nas perspectivas construídas no decorrer dos estudos históricos da humanidade assim como nas diferentes áreas de conhecimento ao qual traz em suas construções conceitos diversos.

Parafraseando Saquet (2007a), é essencial buscar identificar e aprofundar as reflexões sobre território e territorialidade, pois, existe uma relação mútua entre ambos na qual os estudos desenvolvidos sobre estes termos são formados com base nos elementos e ações que realizamos no dia-a-dia.

O processo de produção do território é constituído pelo movimento histórico e por simultaneidades. Há um movimento constante que se materializa na vida cotidiana e no território, centrado na intersecção entre os tempos histórico e coexistente (multiescalar). No território há uma conjugação entre aspectos da economia, da política, da cultura e da natureza exterior ao homem (E-P-C-N). (SAQUET, 2007a, p. 56)

O território envolve qualquer espaço definido e delimitado por e a partir de relações de poder e pelas relações entre os diferentes indivíduos ou grupos. Sabe-se que o espaço é anterior ao território, é o lugar natural. Desse modo, a partir do momento em que habitamos um determinado espaço, o mesmo se transforma num território que é resultado de uma ação. Isso se torna possível porque ao adentrar um espaço, fixamos alguns elementos individuais e coletivos do grupo ocupante.

Nessa perspectiva, Raffestin (1993, p.143) compreende que “[...] evidentemente o território se apoia no espaço, mas não é o espaço. É uma produção, a partir do espaço". Nesse sentido, entende-se que o território é o espaço apropriado por uma relação de poder, ou seja, quando um indivíduo ou uma organização exerce um controle ou um poder sobre um determinado campo, ele passa a ser o seu território, e que envolve muitas relações sociais e de controle no âmbito do poder, a apropriação do espaço ocorre por meio da representação do próprio espaço.

O território pode possuir um caráter que modifica com o tempo ao qual se nos desarticulam mais diferentes espaços e que se organiza a partir de organismos que se misturam pela absorção de informações ou de interruptores. Dessa forma, podemos compreender que o território tem vários níveis, alternando desde a localidade até o global. Além disso, ele pode se expressar por meio de relações naturais ou biológicas, culturais, políticas, sociais, econômicas, entre outras.

Nesse sentido, o território centraliza dentro das relações entre espaço e poder, mas não só ao poder tradicional da própria política de dominação, mas também ao simbólico de "apropriação". Isto é, quando o espaço for habitado, ele se torna um território, que territorializa uma ação. Assim, causando uma expressão de controle ou da influência em um determinado território, o que caracteriza a territorialidade. Dessa forma, compreendemos com Saquet (2007a) que a territorialidade constitui as formas de relações diárias e das atividades cotidianas, em 
qualquer espaço, e momentos que mantemos entre nós para que possamos sobreviver na sociedade de forma biológica.

Para Raffestin (1993) a territorialidade reflete múltiplas dimensões do "vivido" territorial pelos habitantes da sociedade. Os indivíduos vivem ao mesmo tempo por relações existenciais e produtivas, relações estas que são de poder, sendo inevitável, pois, toda relação está ligada ao poder. De acordo com o autor, a noção de territorialidade se encontra por meio da visão naturalista, preocupando com a territorialidade animal, que caracteriza na conduta adotada do organismo para tomar posse de um território e defendê-lo contra outros membros e até os de sua própria espécie.

De acordo com Raffestin (1993), ao compreender a territorialidade como multidimensionalidade na sociedade, afirma que "[...] a territorialidade adquire um valor bem particular, pois reflete a multidimensionalidade do "vivido" territorial pelos membros de uma coletividade, pelas sociedades em geral". (RAFFESTIN, 1993, p. 158). Partindo desse princípio, a territorialidade é entendida como um fenômeno de comportamento associado à organização do espaço ou em territórios diferenciados pelos que os definem e também concebida como uma distância física estabelecida pelas pessoas e um espaço ressignificado pelos mesmos.

Dessa forma, Raffestin (1993), entende que:

Cada sistema territorial segrega sua própria territorialidade, que os indivíduos e as sociedades vivem. A territorialidade se manifesta em todas as escalas espaciais e sociais; ela é consubstancial a todas as relações e seria possível dizer que, de certa forma, é a "face vivida" da "face agida" do poder. (RAFFESTIN, 1993, p. 161-162).

Assim compreendemos que a territorialidade é a concepção que temos do poder exercido por um indivíduo ou, um grupo, em um determinado território e que demonstra domínio, poder e influência dentro do território. A territorialidade é algo mais cultural do que físico. Em um mesmo território, podem ocorrer muitas territorialidades desde as mais firmes às mais incertas, considerando-se a dinâmica dos fatores envolvidos na relação.

\section{PROCESSOS DE DESTERRITORIALIDADE DOS POVOS INDÍGENAS NO ANTIGO NORTE GOIANO}

O que vem ser a desterritorialização? De acordo com Haesbaert (2007) o assunto sobre a desterritorialização é novo, que logo tomou relevância e acabou se expandindo pelos mais diversos âmbitos das Ciências Sociais. A concepção teórica mais elaborada sobre a desterritorialização vem da Filosofia, adquirindo amplitude e relevância nos autores Deleuze e Guattari. 
Segundo Haesbaert (2007), "[...] para Deleuze e Guattari, o pensamento se faz no processo de desterritorialização. Pensar é desterritorializar. Isto quer dizer que o pensamento só é possível na criação, e para se criar algo novo é necessário romper com o território existente, criando outro". (HAESBAERT, 2007, p. 130). Dessa forma, a desterritorialização é sempre seguida de uma reterritorialização, que não ocorre sozinha, ela ocorre pelo menos em dois termos. Desterritorializamos e logo após, reterritorializamos, com um novo sentido. Assim, ainda para Haesbaert (2007, p. 131) "[...] esta reterritorialização é a obra criada, é o novo conceito, é a canção pronta, o quadro finalizado".

Nessa perspectiva, para compreender a desterritorialidade é preciso articular o conceito de território relacionando-o por meio do desejo. Sempre desejamos um agregado de coisas, que vem sempre agenciado e criando territórios, pois compreende uma série de agenciamentos. Entendese por agenciamentos, o movimento de relações múltiplas e complementares, que antes de tudo também é territorial, e são condições para a própria história. (HAESBAERT, 2007).

O poder, o território e a (des) territorialização de um "lugar" estão correlacionados ao campo da relação e ao campo de poder que são componentes das relações de poder, pois de acordo com Saquet (2007b) o território é a cena do poder e o lugar de todas as relações. Para Bourdieu (1989) estes termos trazem consigo uma legitimidade das fronteiras e do mundo social.

Os termos poder, território e (des) territorialização são elementos que estão em constante presença quando se trata de ocupação do lugar chamado norte goiano do século XIX. Haesbaert (2005) afirma que a própria concepção de território esta interligada diretamente aos aspectos da dominação da terra; proporcionando a inserção do terror e do medo, seja pelo dominante ao "proteger" seu território conquistado, seja pelo dominado que são impedidos de entrar no mesmo. O autor ainda interpõe à positividade aos que usufrui deste território a existência de privilégios e a inspiração pelas suas identificações e efetivação da apropriação deste território dominado.

Assim como qualquer território a tomada do mesmo edita diante de dificuldade e medo pelo desconhecido, o início da colonização da Província de Goiás teve como ascendentes a busca pelo ouro e migração de "populações do Norte-Nordeste". A este episódio é abordado no relatório que a Assembleia Legislativa de Goyaz apresentou na sessão ordinária de 1835, o Exm. Presidente Joze Rodrigues Jardim, "A mineração, que em outros tempos atrahio das diferentes Provincias povoadores para Goyaz, se acha em abandono" (RELATORIO APRESENTADO NA ASSEMBLEIA LEGISLATIVA DE GOIÁS, 1835, p.16) percebe-se que após a diminuição do ouro e por consequência da mineração em geral estas populações diminuíram o fluxo deixando para traz uma necessidade do Estado de populacional o seu território.

De certo que a tomada do território da Província de Goiás só se tornou possível pelo garimpo do ouro a partir do século XVII, porém mesmo com as "construções" dos caminhos para que tenha os acessos necessário ao desbravamento do antigo norte goiano ainda assim, existiam as dificuldades de acesso constantes.

Mas não só os caminhos dificultaram a penetração no território goiano. Se, por um lado, o bandeirismo esteve também muito voltado para a caça e escravização do indígena, por outro este 
também resistia duramente aos novos ocupantes do território que lhes pertencia e consequentemente, à destruição de sua cultura. A população indígena pertencia a várias nações, embora haja indícios de que algumas já estivessem em Goiás em decorrência de um processo de interiorização. (AGUIAR, 2003, p. 20) (grifo nosso)

Sendo assim, a construção e ocupação de um território é fracionado ao conhecimento de quem o legitima como tal, ou seja, identifica-se a presença de habitantes, porém não os reconhecem como população vivente daquele território a se ocupar. No decorrer do século XIX as populações que viviam no interior do Goiás, especificamente, no antigo norte goiano eram em sua grande maioria indígenas que buscavam refúgios territoriais.

Assim, se borram e embaçam as fronteiras. Também, o próprio pertencimento socioterritorial tende a fragmentar-se, tornando-se multifocal. Para muitos indivíduos, o pertencimento esgarça-se por uma prolongada ausência de seus lugares, por razões diversas, e, para outros, por exemplo, pelos processos desterritorializantes/reterritorializantes na relação com grupos de outros territórios. (ALMEIDA, 2012, p.164)

Nos diversos relatórios apresentados para a assembleia legislativa da província de Goiás confirmam a necessidade de retirada ou domesticação dos indígenas nos territórios visualizados como produtivo, seja pelo víeis da navegação criando cais de assessoria no percurso dos rios Araguaia e Tocantins ou pelo viés da agricultura/pecuária dos fazendeiros. De certo, é que estes movimentos de deslocação territorial eram "propostos" pelo poder do Estado Provincial.

O poder do Estado agia como intercessor na ocupação do território, visto que buscava colonizar os territórios "desocupados" não só da província do Goiás mais também de todo o território nacional, assim como intercedia nos movimentos de resistência dos indígenas que ocupavam o território desejado pelo desenvolvendo populacional e econômico do poder provincial.

Os principais territórios reivindicados pelo poder Provincial aos indígenas eram as margens dos rios, pois buscavam por meio da navegação dos rios Araguaia e Tocantins estabelecerem uma via fluvial de comércio com as demais províncias de fronteira, o que se tornava inviável pela presença dos indígenas e dos diversos elementos da natureza.

Para diminuir esta diversidade o governo provincial estabeleceu diversos mecanismos/projetos que iriam de ataques pela "defesa do Império" que buscava espantar ou exterminar estes povos indígenas ou por meio do emprego de missões elaboradas pelas Ordens Religiosas que buscavam estabelecer uma forma de domesticar estes indígenas por intermédio da evangelização e ao ensino do "amor ao trabalho".

[...] 4ㅇ) Dar a catequese uma direção nova, de modo que os índios possam servir para tripulação e não fiquem aí ociosos, como até o presente, consumindo anualmente uma verba de 5:000\$000, que se escoa em compre de miçangas, que não aproveitam nem a nós, nem a eles. " (COUTO DE MAGALHÃES, 1974, p.185) 
Em consequência disso, os indígenas deveriam ser utilizados como ferramentas para o bom funcionamento da economia provincial ao servirem como parte da tripulação, seriam utilizados como remadores em troca de um pequeno estipendio, desenvolveria assim uma ligação à verdadeira civilização regida pela ideia de amor pelo trabalho, pela família e pela ordem.

Porém, esta ideia de agregar valores aos povos indígenas como participante ativo da economia provincial não era um pensamento agregado a todos os governantes, pois para muitos governantes, estes indígenas seriam apenas "selvagens" sem valores positivos ao governo e que, portanto, necessitaria extingui-los dos territórios visados.

A população aglomerada na margem esquerda do Tocantins lança vistas sobre a esquerda, onde se encontrao os férteis campos de Amaro Leite infestados pelo feroz, e audaz Canoeiro: empregandose a 2 ㅇ Companhia de Pedestres, que nenhum serviço prestou nos presídios do Araguaya, em rebater as incursões d'este índio; à proporção, que se forem desinfestando esses campos, não deixarão de ser aproveitados por meio da venda das terras, e formar-se hao povoações, que se vao estendendo, ate que em época, talvez não mui remota alcancem a margem direta do mesmo Araguaya; e como o seu curso é quasi desempedido, conseguir-se-há o desideratum da sua navegação, sem disseminar-se a população, e tendo-se extirpado o cancro do Canoeiro. (RELATORIO APRESENTADO NA ASSMBLEIA LEGISLATIVA DE GOIÁS, 1854, p.29)

Percebe-se assim, um constante apelo a desterritorialização dos indígenas nestas regiões. Este mesmo apelo é percebido no decorrer de todas as margens dos rios Tocantins e Araguaia que se fez mais presente quando o Governo Provincial propõe o início do projeto de navegação destes rios.

Percebemos ainda que mesmo os territórios que eram visionados pelo Estado e que outrora faziam moradia as diversos indígenas, e que não eram povoados pela civilização de colonizadores eram propostos à construção de órgãos públicos e não a devolução destes territórios aos moradores anteriores.

[...] O governo Imperial julgou o território de Amaro Leite nas mesmas condicções do das margens do Araguaya, que não poderão attrahir população ainda à custa de consideráveis sacrifícios, e por isto ordenou, que ali se reproduzissem os Presidios; quando pelo contrario os habitantes de toda a Provincia só aspirao à que se desinfestem esses férteis campos das incursões dos selvagens, para occupal-os sem detença. (RELATORIO APRESENTADO NA ASSEMBLEIA LEGISLATIVA DE GOIÁS, 1854, p.30)

Para Haesbaert (2007) considera o Estado um agente desterritorializador e o responsável pelo movimento de desterritorialização, pois na medida em que ele produz a divisão da terra pela organização administrativa, destrói os seus agenciamentos e territórios. De acordo com Haesbaert (2007), Canclini $(1990,1995,1997)$ é um dos autores que aborda o assunto da desterritorialidade a partir do olhar cultural. Para este autor, a desterritorialização é entendida como fruto da fraqueza 
extrema das lealdades nacionais e também as locais em favor das comunidades desterritorializadas de consumidores.

Partindo desse princípio, entende-se que a desterritorialização desde uma extensão cultural, propõe uma desterritorialidade a partir das diversas situações de diálogo cultural que ela implica, pois, para Little (2002) a própria definição de territorialidade parte do esforço coletivo do grupo social que pretende converter o espaço em seu território por meio do ocupar, usar, controlar e identificar com uma parcela especifica de seu ambiente biofísico. Por tanto, a tomada de um território não é tão simples ao viés do dominado ou do dominador, pois ambos têm que se proporem aos esforços do grupo por aquele ambiente visado.

Nesse sentido Haesbaert (2007, p. 229) compreende que:

Assim, teríamos territórios culturalmente mais fechados cujos grupos poderiam ser vistos, ao mesmo tempo, como territorializados (internamente) e desterritorializante (na relação com grupos de outros territórios, deles excluídos), e territórios culturamente mais híbridos, no sentido de permitirem/facilitarem o diálogo intercultural, quem sabe até possibilitando a emergência de novas formas, múltiplas, de identificação cultural.

Este esforço coletivo pelo pertencimento e continuidade do território é identificado nos dois grupos por meio da resistência e dos conflitos entre eles. No relatório no qual o Dr. Francisco Mariani até então Presidente da Província de Goiás informa ao seu sucessor Dr. Antonio Augusto Pereira da Cunha que no ano de 1854 que ordenou os seus destacamentos militares a irem à busca de indígenas que estariam próximas as margens dos rios ou que não estava sobre o poder dos missionários, proporem aos povos indígenas a suas retiradas para o bom desenvolvimento da navegação fluvial.

Empregar os destacamentos assim colocados em bater constantemente as mattas, os da linha de Oeste, na direção do Sul, e os da do Norte na direção de leste, até a margem do Tocantins, procurando encontrar os índios, e não agredindo-os, mas repelindo vigorosamente os seus ataques, à fim de, ou convencel-os das nossas disposições pacificas, ou obrigal-os pelo terror a abandonar essas porções de território, e prosseguir ate impellilos para além do Araguaya. (RELATÓRIO APRESENTADO NA ASSEMBLEIA LEGISLATIVA DE GOIÁS, 1854, p.42)

Em outro momento o presidente de Província Dr. Antonio Candido da Cruz Machado após assumir a presidência da Província de Goiás no mesmo ano de 1854 solicita junto aos missionários que estavam presentes na margem do Araguaia a participação para auxiliarem como intercessores na participação de alguns indígenas da aldeia Chavante para servirem ao estado como intérprete.

[...] recomendei-Ihe, como objeto muito importante de seu ministério, que se transportasse para aquelle ponto, e se esforçasse por inocular nos ânimos dos indígenas sentimentos de paz, hábitos de civilização, e os preceitos da moral christã, que fossem compatíveis com o estado da inteligência d'elles, afagando-os com brindes de objectos, que eles mais apreciassem, como sejão ferramentas, 
e granadas, que para este fim se Ihe remettião; que levasse com sigo alguns índios Chavantes da missão de Jamimbú, que servissem de interpretes, e também seis ou oito praças do destacamento, se julgasse preciso; pois as que ficassem, sendo coadjunvadas pelos habitantes, poderião muito bem rondar as imediações a miúdo, durante a ausência das outras, e evitar assim qualquer hostilidade da parte dos canoeiros. (RELATÓRIO APRESENTADO NA ASSEMBLEIA LEGISLATIVA DE GOIÁs, 1854, p.134).

Percebe-se que existe entre as diversas aldeias pertencentes ao território da Província de Goiás uma ligação "pacífica" entre indígenas e Estado, assim como se percebe a contrapartida da resistência ativa por meio de constantes conflitos por domínio de território.

Vieira (2007, p.35) afirma que a relação entre indígenas e não indígenas não foi construída apenas com conflitos, mas também com constantes negociações levando-os "[...] a uma confluência de valores e costumes recíprocos [...]". Pode-se mencionar, por exemplo, um sistema para a minimização destes conflitos através do relatório que foi apresentado a Assembleia Legislativa de Goyaz na sessão ordinária do ano de 1847 pelo Exm. Presidente da mesma província, doutor Joaquim Ignacio Ramalho. O documento consistia que "[...] para conseguir-se a civilização dos indígenas, o methodo que me parea mais pacifico he o estabelecimento de aldêas nos lugares em que eles mais freguentemente habitão". Este sistema apresentado pelo Presidente poderia simplesmente diminuir com os diversos conflitos existentes pelo domínio de território, porém a ideia não era só isso, este procedimento causaria também uma maior ligação entre os grupos. "[...] d'est'arte hirao se convencendo lentamente de que a raça civilizada não quer a sua destruição, mas antes o seu bem estar; crearão facilmente necessidades, que os obriguem à vida social, onde somente poderão satisfazer-as". (RELATÓRIO APRESENTADO NA ASSEMBLEIA LEGISLATIVA DE GOIÁS, 1847 p. 13)

Ao analisar alguns documentos do período proposto, século XIX, conseguimos localizar uma maior predominância por parte dos povos indígenas da etnia dos Canoeiros, que são denominadas como sendo "uma tribo feroz e muito dividida" causando ao estado grande problema, pois são nômades e, portanto, "[...] não parece susceptivel de civilização, tem um instincto para a carnagem e a rapina, e não se conta que um canoeiro adulto adoptasse aos hábitos do homem civilizado" (RELATÓRIO APRESENTADO NA ASSEMBLEIA LEGISLATIVA DE GOIÁS 1854, p.133).

Para os autores Guattari; Rolnik (1986, p.323) afirmam que:

Os seres existentes se organizam segundo territórios que os delimitam e os articulam aos outros existentes e aos fluxos cósmicos. O território pode ser relativo tanto a um espaço vivido, quanto a um sistema percebido no seio da qual um sujeito se sente "em casa". O território é sinônimo de apropriação, de subjetivação fechada sobre si mesma. Ele é o conjunto de projetos e representações nos quais vai desembocar, pragmaticamente, toda uma série de comportamentos, de investimentos, nos tempos e nos espaços sociais, culturais, estéticos, cognitivos.

Assim surge problemáticas que deverão ser sancionadas posteriormente em nossa pesquisa: como delimitar a concepção de território a uma moradia constituída por nômades? 
Quais as relações colocadas e delimitação de seu território? Estas são questões que trabalharemos em outro momento oportuno.

De certo que, a construção dos conceitos de território dentro das concepções indígenas no século XIX, foi delimitada pelo poder do Estado e consagrado por meio da repressão e tomadas dos territórios propícios ao Estado, poucas sendo as participações do indígena na consolidação de um território próprio.

\section{CONSIDERAÇÕES PARCIAIS}

São diversos os conceitos associados ao território e seus relativos termos, assim como, a própria concepção de território se liga ao conceito de territorialidade interpondo por fim ao conceito de desterritorialização. Estes termos estão interligados quando se trata das tomadas dos territórios indígenas pelo estado pela e para o desenvolvimento da província de Goiás no século XIX.

Concepções de território e territorialidade no antigo Norte Goiano contribui para que compreendemos a ocupação dos territórios pelos bandeirantes aos povos indígenas que viviam ali. Compreendemos ainda que com isso houve procesos de desterritorialização submetendo de maneira forçada a esses sujeitos que se (re) territorializem em outro espaço assumindo outros territórios.

Estas tomadas de território proporcionaram à história uma diversidade de fatos voltados para o conflito e para a resistência, seja pelo indígena para a sua permanência ao território ocupado, levando em conta sua sobrevivência, cultura, economia entre outros, seja pelo não indígena que a dominou posteriormente construindo ali uma nova concepção de território ocupado.

Dessa forma, dependendo da perspectiva, podemos ter múltiplos territórios, nas mais distintas localidades, modificando a partir de pequenos e até grandes componentes do espaço. Portanto, o entendimento de como atuam os territórios, contribui para a melhor compreensão do mundo em que vivemos e das relações de poder que nele permanece.

Contudo, temos plena consciência de que essa sistematização do processo de desterritorialização no antigo norte goiano tendo como foco as retiradas dos indígenas de seus territórios e como eram vistos pelo poder provincial goiano, não se encerra por aqui, ao contrário, nos provoca a ampliarmos cada vez mais o diálogo e aprofundar em suas construções.

\section{REFERÊNCIAS}

AGUIAR, M. do A. A. (2003). Terras de Goiás: estrutura fundiária (1850-1920). Goiânia: Ed. UFG.

ALMEIDA, M. G. (2012). Fronteiras sociais e identidades no território do complexo da usina hidrelétrica da Serra da Mesa-Brasil. In: BARTHE-DELOIZY, F., and SERPA, A., orgs. Visões do 
Brasil: estudos culturais em Geografia [online]. Salvador: EDUFBA; Edições L'Harmattan. Recuperado de http://books.scielo.org/id/8pk8p/pdf/barthe-9788523212384-09.pdf.

BRASIL. Relatório que á Assembleia Legislativa de Goyaz apresentou na sessão ordinaria de 1837 o exm. presidente da mesma província Presidente Joze Rodrigues Jardim. Goyaz, Typ. Provincial, 1837. Recuperado de http://www-apps.crl.edu/brazil/provincial

BRASIL. Relatório que á Assembleia Legislativa de Goiás apresentou na sessão ordinária de 1847 o Exm. Presidente da mesma província, Dr. Joaquim Ignacio Ramalho. Goyaz, Typ. Provincial, 1847. Recuperado de http://www-apps.crl.edu/brazil/provincial.

BRASIL. Relatório que á Assembleia Legislativa de Goiás apresentou na sessão ordinária de 1854 o Exm. Presidente da mesma província, Dr. Antonio Candido da Cruz Machado. Goyaz, Typ. Provincial, 1854. Recuperado de http://www-apps.crl.edu/brazil/provincial.

BOURDIEU, P. (1989). "A Identidade e a Representação: elementos para uma reflexão crítica da ideia de região". In. . O Poder Simbólico. Rio de Janeiro: Bertrand Brasil.

COUTO DE MAGALHÃES, J. V. (1974). Viagem ao Araguaia. São Paulo: Três.

GUATTARI, R. S. (1996). Micropolítica: cartografias do desejo. Petrópolis: Vozes.

HAESBAERT, R. (2005, março). Da Desterritorialização á Multiterritorialidade. Anais do X Encontro de Geógrafos da América Latina, São Paulo, SP, Brasil. Recuperado de http://observatoriogeograficoamericalatina.org.mx/egal10/Teoriaymetodo/Conceptuales/19. pdf.

HAESBAERT, R. (2007). O mito da desterritorialização: do "Fim dos Territórios" à Multiterritorialidade. 3 a ed. Rio de Janeiro: Bertrand Brasil.

LITTLE, P. E. (2002). Territórios Sociais e Povos Tradicionais no Brasil: Por uma antropologia da territorialidade. Série Antropologia. Brasília.

RAFFESTIN, C.. (1993). Por uma geografia do poder. Tradução de Maria Cecília França. São Paulo: Ática.

SAQUET, M. A. (2007a). Abordagens e concepções sobre território. São Paulo: Expressão Popular.

SAQUET, M. A. (2007b). As diferentes abordagens do território e a apreensão do movimento e da (i)materialidade. Revista Geosul, Florianópolis, v. 22, n. 43, 55-76. Recuperado de https://periodicos.ufsc.br/index.php/geosul/article/view/12646.

VIEIRA, M. V.. (2007). Ordem pública, catequese e civilização na província de Goiás. História Revista, Goiânia, v. 12, n. 1, 27-38. Recuperado de https://revistas.ufg.br/historia/article/view/6846/4907. doi: https://doi.org/10.5216/hr.v12i1.6846. 